\title{
The evidence of temporary social parasitism by Polyrhachis lamellidens (Hymenoptera, Formicidae) in a Camponotus obscuripes colony (Hymenoptera, Formicidae)
}

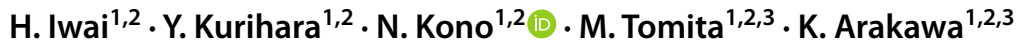

Received: 12 February 2021 / Revised: 5 June 2021 / Accepted: 11 August 2021 / Published online: 22 August 2021

(c) The Author(s) 2021

\begin{abstract}
Polyrhachis lamellidens is a temporary socially parasitic ant whose new queen utilizes other ant species in the early stages of colony foundation. Field observations and rearing experiments suggest that Camponotus japonicus is a host species of P. lamellidens. It is presumed that Camponotus obscuripes is also a host of P. lamellidens by rearing experiments and field observations; however, there are no records of P. lamellidens workers or brood coexisting in C. obscuripes colonies in field observations, and there is no clear evidence that $C$. obscuripes is a natural host of $P$. lamellidens. We conducted detailed field observations, behavioral tests, and rearing experiments to show that $C$. obscuripes is a host of temporary social parasites. We found colonies with $P$. lamellidens queens, workers, and larvae intermixed with $C$. obscuripes workers in the field. Behavioral tests showed that workers of both species in mixed colonies did not attack each other and maintained nestmate recognition ability, which suggests a collaborative nestmate relationship. Furthermore, a rearing experiment confirmed social parasitism by $P$. lamellidens among $C$. obscuripes by producing a mixed brood-producing colony. These are the first field and laboratory records of temporary social parasitism involving P. lamellidens and C. obscuripes.
\end{abstract}

Keywords Social parasite $\cdot$ Host record $\cdot$ Rearing experiment $\cdot$ Polyrhachis lamellidens

\section{Introduction}

Polyrhachis lamellidens is a temporary social parasite that establishes new colonies with the assistance of a host species (Yano 1911; Kohriba 1963, 1966; Kubota 1974; Sakai 1996, 2000; Japanese Ant Database Group 2003; Furukawa et al. 2012) and is a known host of myrmecophiles (Iwai et al. 2016). P. lamellidens queens allow their host workers to care for their parasitic brood (eggs, larva, and pupa), resulting in a temporary period during which host-reared $P$. lamellidens workers and host workers inhabit the same colony (Kohriba

H. Iwai and Y. Kurihara contributed equally.

N. Kono

ciconia@sfc.keio.ac.jp

1 Graduate School of Media and Governance, Keio University, Fujisawa, Japan

2 Institute for Advanced Biosciences, Keio University, Tsuruoka, Japan

3 Faculty of Environment and Information Studies, Keio University, Fujisawa, Japan
1963; Sakai 2000; Japanese Ant Database Group 2003). This mixed colony transitions to a $P$. lamellidens-only colony as the number of host workers gradually decreases (Japanese Ant Database Group 2003). Several species (Camponotus japonicus, Camponotus obscuripes, and Camponotus kiusiuensis) have been suggested to be hosts of P. lamellidens (Yano 1911; Kohriba 1963, 1966; Kubota 1974; Sakai 1990, 1996, 2000; Japanese Ant Database Group 2003; Furukawa et al. 2012). C. japonicus has been confirmed as a host species according to observations of mixed colonies of $P$. lamellidens and C. japonicus. In mixed colonies in the field, the two different species coexisted without any aggressive behavior towards one other (Kohriba 1966). In addition, Kohriba demonstrated the early conditions of parasitic life in a laboratory environment and even observed brood production by P. lamellidens (Kohriba 1963).

There have been reports of new queens of $P$. lamellidens exhibiting an initial performance (the behavior of straddling host workers, which is speculated to promote invading the host colony) towards $C$. obscuripes workers and inhabiting C. obscuripes colonies (Sakai 1996; Furukawa et al. 2012). These findings suggest that $C$. obscuripes serves as a host 
for the temporary social parasite P. lamellidens. However, to accept this hypothesis, the following three factors must be examined and confirmed: parasite brood production, nestmate discrimination, and parasitism style. Parasite brood production is a primary event required to complete the social parasitism cycle (Hölldobler and Wilson 1990; Buschinger 2009; de la Mora et al. 2020). If C. obscuripes serves as the host, then $P$. lamellidens workers and brood must be identified along with $C$. obscuripes. However, $P$. lamellidens workers and brood have not yet been found in C. obscuripes colonies in the field or under artificial rearing conditions. Nestmate discrimination, i.e., whether $C$. obscuripes workers accept the parasites as nestmates must also be verified. Since a parasite and its host inhabit the same colony, they must recognize each other as nestmates while exhibiting aggressive behavior towards nonnestmates. Furthermore, it is necessary to show that $P$. lamellidens utilizes C. obscuripes as a host for temporary social parasitism and not other types of parasitism. In temporary socially parasitic ants, such as P. lamellidens and $C$. japonicus mentioned above, temporary coexistence between parasites and hosts occurs after killing the host queen.

The coexistence of parasites and hosts has also been shown in other social parasite strategies, such as xenobiosis and inquilinism, but these strategies do not result in the killing of a host queen by the parasite (Hölldobler and Wilson 1990; Buschinger 2009; de la Mora et al. 2020). For example, Polyrhachis lama (Formicidae: Formicinae) and Polyrhachis loweryi (Formicidae: Formicinae) have been identified as socially parasitic species (xenobiosis) of Polyrhachis species other than P. lamellidens (Maschwitz et al. 2000, 2003), and they do not kill the host queen. Dulotic species also kill the host queen; however, the subsequent coexistence with the host colony is permanent (because host workers are continually supplied by slave raiding), and they do not eventually replace the colony as some temporary socially parasitic ants do (Hölldobler and Wilson 1990; Buschinger 2009; de la Mora et al. 2020). Dulotic species are strictly divided into obligatory dulosis and facultative dulosis, in which the former worker, lacks the working ability while the latter possesses it. If $P$. lamellidens utilizes $C$. obscuripes as a host, then it is necessary to show that the $C$. obscuripes queen is killed by the P. lamellidens queen and that $P$. lamellidens workers are able to survive in the absence of their host. Therefore, exploration of mixed colonies in the field, behavioral tests, and rearing experiments are necessary to show that $C$. obscuripes is a host of temporary social parasites.

In this paper, we report the first record of a mixed colony consisting of $C$. obscuripes workers and a P. lamellidens queen, workers, and brood from Yamagata Prefecture, Japan. Two independent mixed colonies were found in the field, and the symbiotic relationship was confirmed by behavioral tests. We also confirmed through rearing experiments that $P$. lamellidens queens practice social parasitism against $C$. obscuripes. These observations indicate that $P$. lamellidens can complete the social parasitism cycle using $C$. obscuripes as a natural host.

\section{Materials and methods}

\section{Sampling and rearing}

Ant colony samples were collected in Yamagata and Niigata Prefecture, Japan (2019 to 2020). Two mixed colonies of $P$. lamellidens and $C$. obscuripes were sampled from a primeval beech forest in Oguni-machi, Yamagata Prefecture (N 3755'13", E 139 40'54"; N 3755'24", E $\left.139^{\circ} 40^{\prime} 27^{\prime \prime}\right)$ and named colony A and B, respectively. Each colony $(\mathrm{A}: \mathrm{B})$ consisted of a P. lamellidens queen, a worker, a larva, and a $C$. obscuripes worker in the following numbers: $1: 1,729: 12,200: 244$, and 31:112. None included the queen and larva of $C$. obscuripes (Table 1). The P. lamellidens and C. obscuripes workers used in the behavioral test and the rearing experiment were collected from free-living colonies. Two free-living $C$. obscuripes colonies not parasitized by $P$. lamellidens were collected from a primeval beech forest in Oguni-machi (N $\left.38^{\circ} 08^{\prime} 48^{\prime \prime}, \mathrm{E} 139^{\circ} 50^{\prime} 35^{\prime \prime}\right)$ and a mixed forest in Tsuruoka City, Yamagata Prefecture (N 38 33'49", E 139 $55^{\circ} 31^{\prime \prime}$ ); the average colony size consisted of one queen and 300 workers. One free-living P. lamellidens colony was collected from mixed forests (N 38 $41^{\prime} 43^{\prime \prime}$, E $139^{\circ} 48^{\prime \prime} 2^{\prime \prime}$ ); the colony size consisted of 20 workers. Eight newly mated $P$. lamellidens queens were collected after finishing their nuptial flights from a mixed forest in Nagaoka City, Niigata Prefecture (N 37 $25^{\prime} 51^{\prime \prime}$, E $\left.138^{\circ} 52^{\prime} 53^{\prime \prime}\right)$. Each collected ant colony was reared separately in a plastic tub $(10.0 \mathrm{~cm}$ in length, $10.0 \mathrm{~cm}$ in width, $2.9 \mathrm{~cm}$ in height, or $27.0 \mathrm{~cm}$ in length, $19.0 \mathrm{~cm}$ in width, $5.1 \mathrm{~cm}$ in height) in which plaster was laid and a feeding area was established
Table 1 Compositions of the two mixed colonies

\begin{tabular}{lllllllll}
\hline & \multicolumn{2}{l}{ P. lamellidens } & & & \multicolumn{3}{l}{ C. obscuripes } & \\
\cline { 2 - 3 } & Queen & Workers & Larvae & & Queen & Workers & Larvae \\
\hline Colony A & 1 & 729 & $>200$ & & 0 & 31 & 0 \\
Colony B & 1 & 12 & 244 & & 0 & 112 & 0 \\
\hline
\end{tabular}


or in a plastic cup $(9.5 \mathrm{~cm}$ in diameter, $4.5 \mathrm{~cm}$ in height) in which moistened tissue was laid. Newly mated P. lamellidens queens were reared individually in a plastic tub that was $4.5 \mathrm{~cm}$ in length, $2.5 \mathrm{~cm}$ in width, and $2.0 \mathrm{~cm}$ in height and contained moistened tissue. The ants were fed 5-5000 $\mu \mathrm{l}$ of 50\% maple syrup (Maple Farms Japan, Limited, Osaka, Japan) every 4-10 days. Worker ants were also fed mealworms and/or 8-16 g of Pro Jelly for beetles and stag beetles (Wraios, Limited, Saitama, Japan). Mixed colonies and non-mixed colonies (C. obscuripes and $P$. lamellidens) were reared under either dark conditions at $15-25{ }^{\circ} \mathrm{C}$ or light:dark conditions (14L:10D) at $20-30{ }^{\circ} \mathrm{C}$. The colonies experimentally invaded by $P$. lamellidens were reared in a cool incubator (Mitsubishi Electric Engineering Company, Limited, Tokyo, Japan) under dark conditions at $20-25{ }^{\circ} \mathrm{C}$. Newly mated P. lamellidens queens were reared in a cool incubator under dark conditions at $15-20{ }^{\circ} \mathrm{C}$. The identifications were performed based on morphological characteristics (referring to Japanese Ant Database Group 2003) and the mitochondrial genes encoding cytochrome oxidase subunits I and II (COI/II) in the NCBI database (http://www.ncbi.nlm.nih.gov). DNA was extracted from the legs by crushing them with a disposable homogenizer and treating them with proteinase $\mathrm{K}$. Extracted DNA was amplified by PCR with the following conditions: $98^{\circ} \mathrm{C}$ for $2 \mathrm{~min}, 30$ cycles each of $98{ }^{\circ} \mathrm{C}$ for $10 \mathrm{~s}, 55^{\circ} \mathrm{C}$ for $15 \mathrm{~s}$, and $72{ }^{\circ} \mathrm{C}$ for 2 min with LifeECO Thermal Cycler (Bioer, China). The Sanger sequencing of the amplified DNA was performed by Eurofins Genomics (Tokyo, Japan). C1-J-1754F (CCACGTTTAAATAATATA AGATTTTGAC) and C2-N-3661R (CCACAAATTTCT GAACATTGACCA) were used as PCR primers (Degnan et al. 2004; Simon et al. 1994). Sequences from P. lamellidens and $C$. obscuripes from mixed colonies and freeliving were confirmed by matching each species by alignment and clustering with MAFFT v7 (Kuraku et al. 2013).

\section{Behavioral tests}

Behavioral tests were conducted in a plastic tub $(8.0 \times 4.0 \times 3.0 \mathrm{~cm})$, with one worker ant from each colony (the mixed Colony A, the free-living C. obscuripes colony, and the free-living $P$. lamellidens colony) encountering others. Mixed colony B was not used for behavioral tests because of the low number of $P$. lamellidens workers. The ants were selected at random and used only once in each test. The workers used for the test were transferred to another case and were not duplicated in subsequent tests. For $30 \mathrm{~s}$, after introducing each ant into the case, a partition was used to prevent contact, reduce stress, and calm their behavior. The first behavior noted during the first contact in less than 6 min after the removal of the partition was recorded according to the following definitions:

- Ignore: the ant does not respond aggressively to contact with the target.

- Threat: the ant opens its mandibles or keeps its distance from the target.

- Rush: the ant approaches and quickly bites the target.

- Bite: the ant continuously bites the target.

Among these behaviors, "Threat", "Rush", and "Bite" were considered aggressive behaviors.

\section{Rearing experiments involving temporary social parasite}

The study of temporary social parasitism in a laboratory environment was conducted based on previously reported procedures (Kohriba 1963). Assays to study initial contact between a newly mated $P$. lamellidens queen and a $C$. obscuripes worker were performed in well-ventilated tubes $(1.0 \times 8.0 \mathrm{~cm})$. For eight newly mated $P$. lamellidens queens, one to twenty free-living $C$. obscuripes workers were placed in the tube every other day. After several days, when contact with more than 60 C. obscuripes workers was observed, the $P$. lamellidens queen was transferred to an empty plastic tub without the $C$. obscuripes queen $(10.0 \times 10.0 \times 2.9 \mathrm{~cm})$. Once it was confirmed that the $C$. obscuripes workers were not attacking the transferred P. lamellidens queen, she was allowed to contact the $C$. obscuripes queen. The C. obscuripes queen was subjected to anesthesia by freezing $\left(4{ }^{\circ} \mathrm{C}\right.$ for $2 \mathrm{~min},-20{ }^{\circ} \mathrm{C}$ for $10 \mathrm{~min}$ ) before contact with a new $P$. lamellidens queen. A newly mated $P$. lamellidens queen is often attacked by the $C$. obscuripes workers or queens, as observed in rearing experiments in previous studies (Sakai 1996, 2000). Since the purpose of this rearing experiment was to learn whether the newly mated $P$. lamellidens queen would recognize the $C$. obscuripes queen as her host, to exclude the possibility of counterattack by the C. obscuripes queen, we conducted the anesthesia treatment.

\section{Results}

\section{Field observations and mixed colony composition}

Two mixed P. lamellidens and C. obscuripes colonies were found inside fallen beech trees in Yamagata, Japan. A queen, larvae, and workers of $P$. lamellidens and workers of $C$. obscuripes coexisted in the same colony (Fig. 1a; Table 1). The balance of worker numbers between $P$. lamellidens and $C$. obscuripes was biased towards $P$. lamellidens in Colony A and C. obscuripes in Colony B (Table 1). We used only 


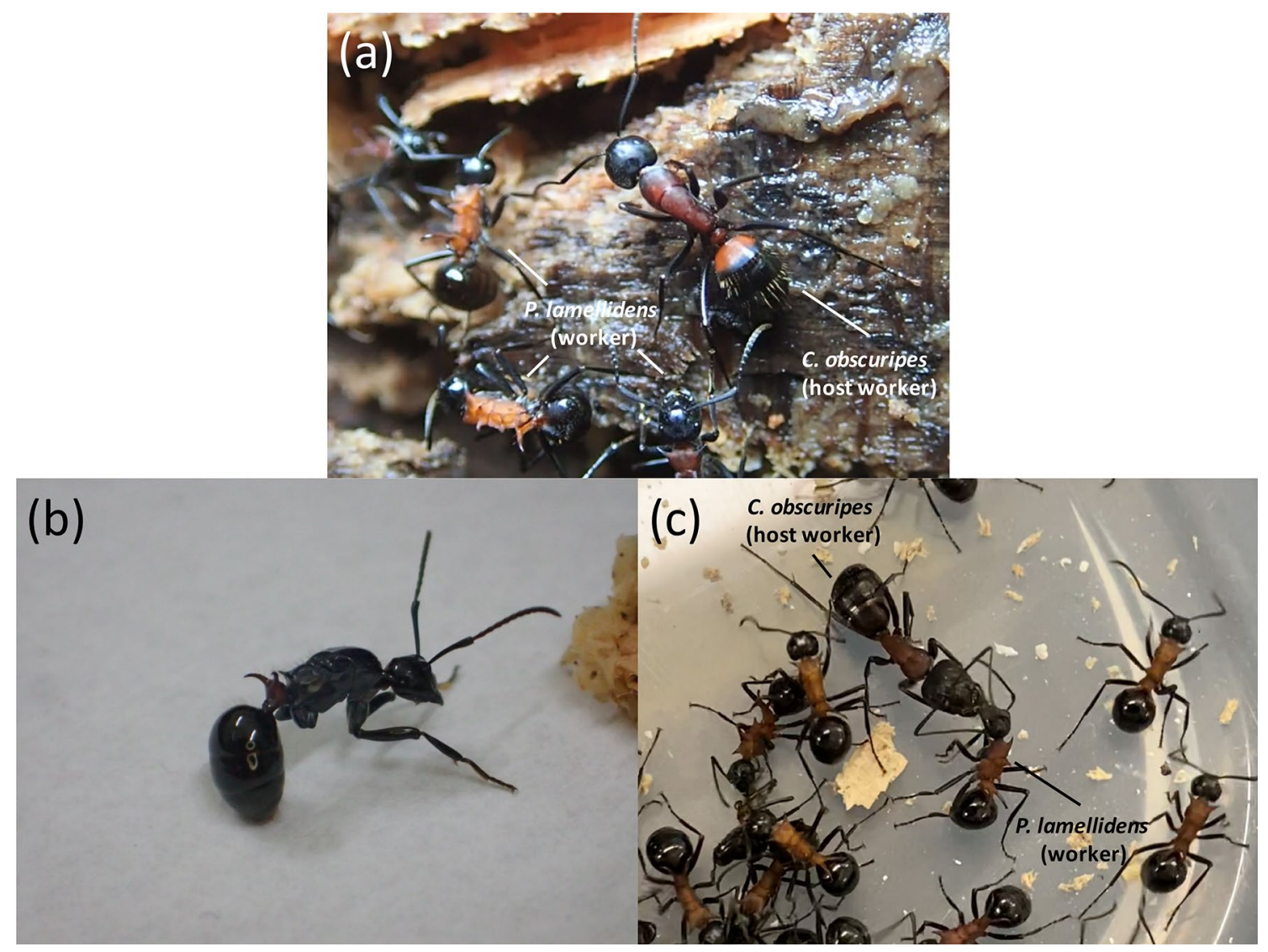

Fig. 1 a P. lamellidens and C. obscuripes were collected from the same colony (a Colony A). b P. lamellidens queen isolated from Colony A. This queen's left and right mid and hind legs were all severed at the base. c P. lamellidens and C. obscuripes perform trophallaxis (Colony A)

Colony A in the behavioral test because the number of $P$. lamellidens workers at Colony B was small. Only one $P$. lamellidens queen was found in each colony. In addition, the P. lamellidens queen found in Colony A possessed left and right mid- and hindlegs that were all severed at their bases (Fig. 1b). After collection, no signs of mutual aggression were observed between the two species in the mixed colonies in the field and under laboratory conditions. Under laboratory-rearing conditions, trophallaxis between $C$. obscuripes and $P$. lamellidens workers was observed (Fig. 1c). All $C$. obscuripes workers (host workers) belonging to Colony A died within approximately 2 months after collection. The $P$. lamellidens colony has persisted to the present day (as of October 2020). The ants in the colonies were identified as $P$. lamellidens and C. obscuripes by comparing the COI/II sequences of non-parasitized $C$. obscuripes and free-living P. lamellidens.

\section{Behavioral tests}

Behavioral tests were performed to quantitatively determine whether the mixed colony composition was a result of temporary social parasitism by P. lamellidens. When
C. obscuripes and P. lamellidens workers from the same mixed colony contacted one another, no aggressive behaviors were observed (Table 2). To exclude the possibility that these workers obtained from the mixed colonies were deficient in the ability to recognize their nestmates, each worker was placed in a container with a worker from a different unparasitized colony. Both species showed clear aggressive behaviors towards the other species (Table 2). These results indicate that $P$. lamellidens and $C$. obscuripes inhabiting a mixed colony are able to recognize each other as nestmates.

\section{Artificial social parasitism rearing experiment}

To observe the initial stages of parasitism by $P$. lamellidens among $C$. obscuripes in a laboratory environment, we conducted rearing experiments. All newly mated P. lamellidens queens collected from the field were reared in the laboratory for more than 6 months. First, we allowed eight newly mated $P$. lamellidens queens to contact non-parasitized $C$. obscuripes workers in a well-ventilated tube individually. As in previous studies, the newly mated $P$. lamellidens queen straddled the host worker and rubbed their body with their legs (Kohriba 1963; Kubota 1974; Sakai 1990, 2000; 
Table 2 The presence of aggressive behaviors in each colony $(n=10)$

\begin{tabular}{|c|c|c|c|c|}
\hline & $\begin{array}{l}P \text {. lam (mixed colony) vs } C \text {. } \\
\text { obs (mixed colony) }\end{array}$ & $\begin{array}{l}\text { P. lam (normal colony) vs } C \text {. } \\
\text { obs (normal colony) }\end{array}$ & $\begin{array}{l}\text { P. lam (mixed colony) vs } C . o b s \\
\text { (normal colony) }\end{array}$ & $\begin{array}{l}\text { P. lam (normal colony) } \\
\text { vs } C \text {. obs (mixed colony) }\end{array}$ \\
\hline \multicolumn{5}{|c|}{ Aggressive behavior } \\
\hline Threat & 0 & 9 & 4 & 1 \\
\hline Rush & 0 & 1 & 5 & 6 \\
\hline Bite & 0 & 0 & 0 & 3 \\
\hline \multicolumn{5}{|c|}{ Non-aggressive behavior } \\
\hline Ignore & 10 & 0 & $1^{*}$ & 0 \\
\hline
\end{tabular}

All tests showed common tendencies in both species to initiate or not initiate aggressive behavior. We used a mixed colony (Colony A) and normal colonies without hosts or parasites (P. lamellidens, C. obscuripes) in the behavioral tests

P. lam P. lamellidens, C. obs C. obscuripes

*In only one out of ten tests, aggressive behavior was initiated on the second contact, not the first

Japanese Ant Database Group 2003). Although no quantitative records exist, some newly mated $P$. lamellidens queens died while contacting the host workers. As a result of this phenomenon that appears to host's attack, five out of eight newly mated $P$. lamellidens queens survived the contact process with $C$. obscuripes workers. After sufficient contact with $C$. obscuripes workers, one of the five surviving newly mated the $P$. lamellidens queen met the non-parasitized $C$. obscuripes queen. The newly mated $P$. lamellidens queen immediately bit the $C$. obscuripes queen's neck (Fig. 2a). This biting behavior continued for 3 days, and eventually, the C. obscuripes queen's head was severed (Fig. 2b). This
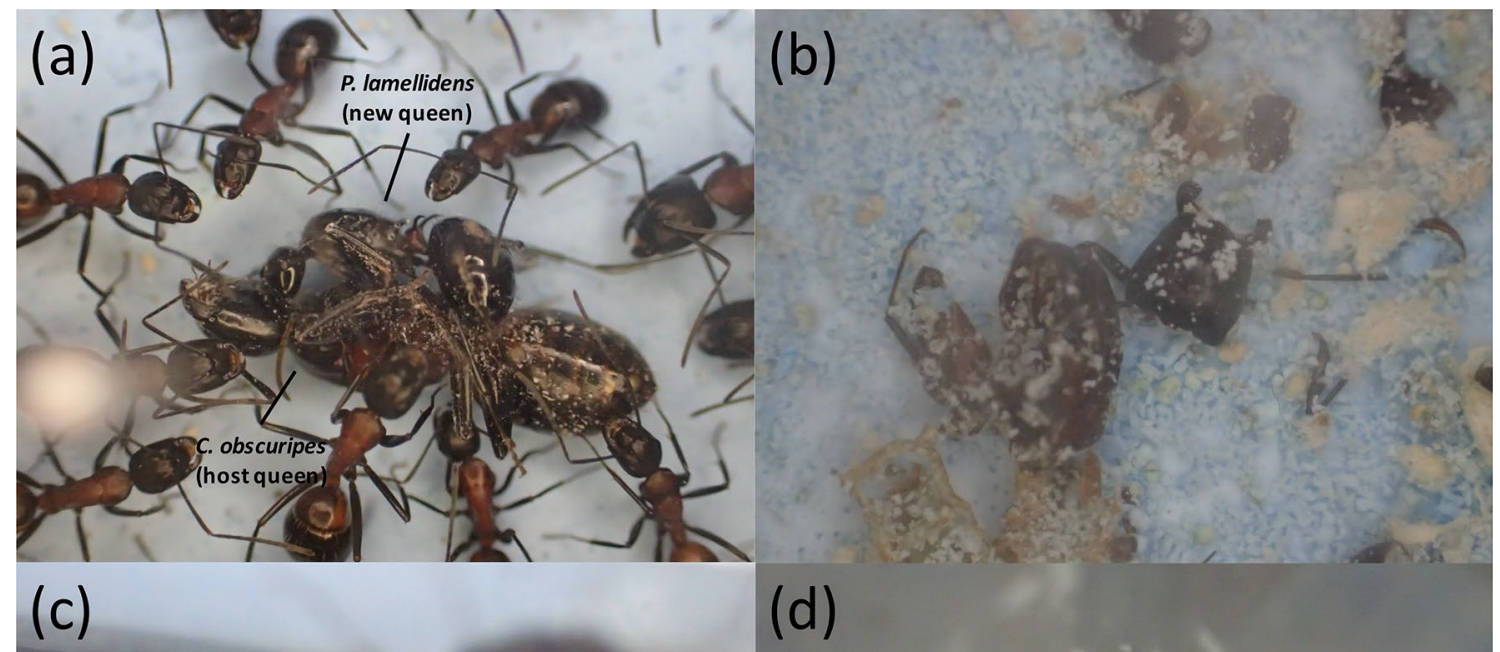

(d)
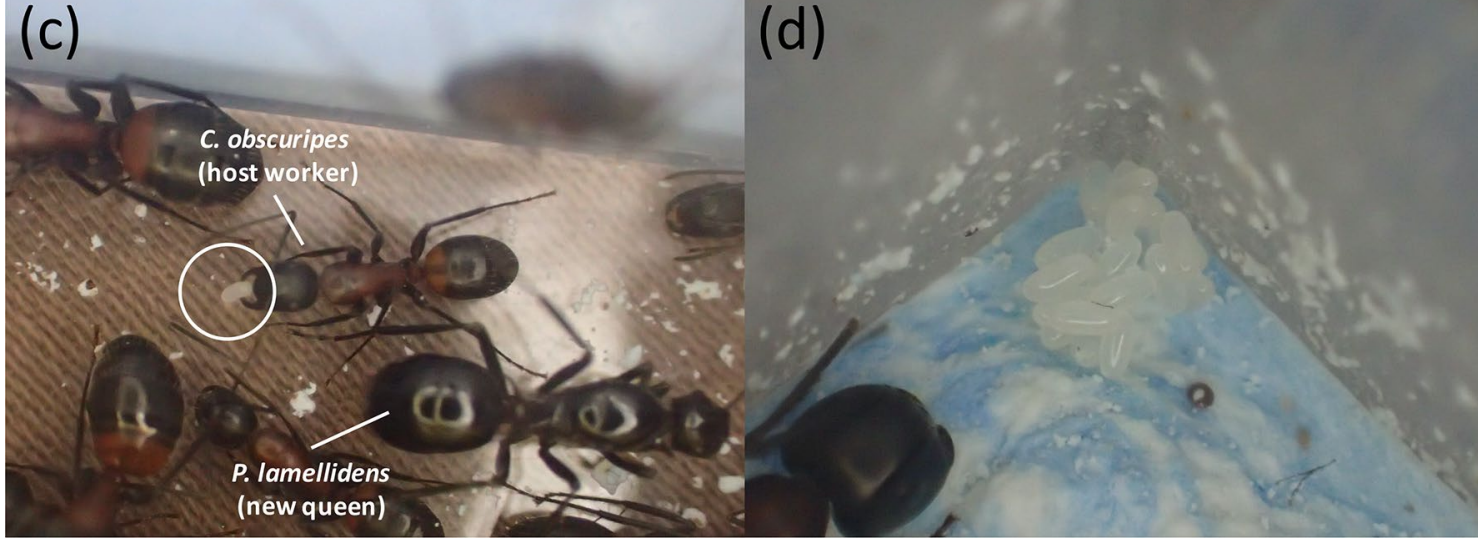

Fig. 2 The early stage of the parasitism cycle. a The new P. lamellidens queen bites the neck of the $C$. obscuripes queen. b The $C$. obscuripes queen after being attacked for 3 days. c Eggs laid by the parasite queen ( $P$. lamellidens) in the host (C. obscuripes) colony. $P$. lamellidens eggs were laid after the killing of the $C$. obscuripes queen. $\mathbf{d} P$. lamellidens eggs were gathered by $C$. obscuripes workers 
killing behavior against the $C$. obscuripes queen was distinctly different from common bite attacks (as described in "Materials and methods"). The newly mated P. lamellidens queen started laying eggs four days after killing the C. obscuripes queen (Fig. 2c). More than ten eggs were confirmed within a week of the first oviposition. P. lamellidens eggs were collected and cared for by $C$. obscuripes workers (Fig. 2d). Between the killing of the host queen and oviposition, C. obscuripes workers did not show any aggressive behaviors towards the newly mated $P$. lamellidens queen.

\section{Discussion}

C. obscuripes has been suggested as a possible host for $P$. lamellidens (Sakai 1996; Furukawa et al. 2012), but there was no conclusive evidence. This paper is the first record of a mixed colony of $C$. obscuripes and P. lamellidens in the field, and P. lamellidens parasitism of $C$. obscuripes colonies was confirmed in a rearing experiment.

In the behavioral tests, $P$. lamellidens and $C$. obscuripes workers from the same mixed colony showed aggressive behavior towards workers from other colonies. Nevertheless, they recognized each other as nestmates, even though they were different species (Table 2). However, non-parasitized $C$. obscuripes exhibited distinct aggressive behaviors towards $P$. lamellidens. These results suggest that both species inhabit the mixed colony as nestmates. It is thought that a newly mated $P$. lamellidens queen will kill the host queen in the early stages of social parasitism according to the previous knowledge of $C$. japonicus as its host (Japanese Ant Database Group 2003). We carried out rearing experiments to verify that $C$. obscuripes is affected by social parasitism. In our rearing experiment, we observed that the $P$. lamellidens queens started laying eggs after killing the host queen (Fig. 2). Thus, we anesthetized the C. obscuripes queen before contacting the newly mated $P$. lamellidens queen in the rearing experiment. However, since the newly mated $P$. lamellidens queen demonstrated the same killing process toward $C$. japonicus, as shown only in the case of a C. obscuripes queen in previous studies (Japanese Ant Database Group 2003), we believe anesthesia does not affect the hypothesis verification of this experiment. Host-queen killing and oviposition in the host colony are common features of temporary socially parasitic and dulotic ants, not xenobiosis and inquilinism (Hölldobler and Wilson 1990; Buschinger 2009; de la Mora et al. 2020). P. lamellidens persisted after the death of the host workers in mixed Colony A. Temporary coexistence with the host and sustaining the colony after the host's death are unique characteristics in temporary socially parasitic ants, not dulotic ants (with some exceptions, e.g., facultatively dulotic ants) (Hölldobler and Wilson 1990; Buschinger 2009; de la Mora et al. 2020).
Based on these observations, the two colonies obtained from the field provide evidence of $P$. lamellidens completing the temporary social parasitism cycle in a $C$. obscuripes colony, and we have clear evidence that $C$. obscuripes is a natural host for $P$. lamellidens. The above experiments and observations verified that $P$. lamellidens is not an obligatorily dulotic ant, as they could persist after the death of the host workers. However, the possibility of facultative dulosis has not yet been rejected. None of the reports of raiding behavior in the field or a few records of the mixed colony with its hosts suggests that $P$. lamellidens is an unlikely facultatively dulotic ant; thus, further verification is needed.

The balance of worker numbers in the two mixed colonies was different (Table 1). We speculate that this reflects the difference in the time that has elapsed since the host queen was killed. Probably, Colony A had been around longer than Colony B since the killing of the host queen; therefore, it had fewer workers of $C$. obscuripes than P. lamellidens. The left and right mid- and hindlegs of the P. lamellidens queen in Colony A were all severed at their bases (Fig. 1b). In past fieldwork (unpublished) in another region [Nirasaki City,

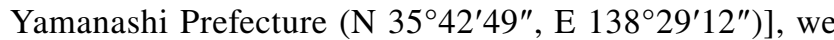
observed an injured P. lamellidens queen from a free-living $P$. lamellidens colony. After the nuptial flight, a newly mated $P$. lamellidens queen invades a host colony to establish a new colony, but she is often attacked by some host workers at first contact, as observed in rearing experiments in previous studies (Kohriba 1963; Sakai 1996, 2000). In this rearing experiment, a newly mated $P$. lamellidens queen, probably killed by an attack from its host workers, has been confirmed. We believe that the P. lamellidens queen of Colony A succeeded in usurping the host colony before being killed by attack by host workers in the early stages of social parasitism.

C. obscuripes workers, members of the collected mixed colony, and those whose queen was killed in the rearing experiment did not show aggressive behaviors towards $P$. lamellidens, and both species coexisted as nestmates. This phenomenon suggests that $P$. lamellidens may have some involvement in nestmate discrimination by $C$. obscuripes. It is known that some socially parasitic ants alter host-like cuticular hydrocarbon $(\mathrm{CHC})$ profiles or express almost no CHCs, which promotes coexistence with their host (Dettner and Liepert 1994; Johnson et al. 2001; Lenoir et al. 2001; Akino 2008; de la Mora et al. 2020). P. lamellidens queens and workers in mixed colonies may utilize similar strategies. The behavior of straddling host workers was observed in P. lamellidens queens. As a previous study speculated (Kohriba 1963), P. lamellidens queens may disguise their $\mathrm{CHC}$ profiles by performing this behavior, enabling invasion of the host colony.

The host Diacamma sp. and Rhytidoponera sp. workers (Formicidae, Ponerinae) of Polyrhachis lama and Polyrhachis loweryi do not rear parasites' brood (Maschwitz et al. 
2003; Witte et al. 2009). It is speculated that the reason for the lack of brood care by the host is that the parasite/host is distantly related at the subfamily level, and there are discrepancies in larval feeding methods (Formicinae larvae receive liquid nourishment that is preprocessed by workers, whereas Ponerinae larvae are provided unmodified prey particles by workers); thus, the rearing style of the host species is not compatible with the parasite brood (Witte et al. 2009). Conversely, in the case of P. lamellidens, the hosts $C$. japonicus and $C$. obscuripes were observed rearing $P$. lamellidens brood (Fig. 2c, d; Kohriba 1963). P. lamellidens and its host ants are relatively closely related, and although they differ at the genus level, they both belong to the subfamily Formicinae (Brady et al. 2006) and probably share a common feeding method. The differences in the presence or absence of brood care by the host, even among socially parasitic species in the genus Polyrhachis, may be related to common brood feeding methods between parasites and hosts, as described above.

The nesting styles of $P$. lamellidens and its host differ. Initial nesting sites of $P$. lamellidens ( $P$. lamellidens changes its nesting site at the end of the social parasitism cycle) are tree hollows, while $C$. japonicus nests in soil and $C$. obscuripes nests in decaying wood (Japanese Ant Database Group 2003). Thus, $P$. lamellidens is relatively unusual as a socially parasitic ant. The exact explanation for why $P$. lamellidens utilizes Camponotus as its host is unclear, but it is likely that $P$. lamellidens has high adaptability to various environments that harbor Camponotus.

Morphological similarities (e.g., body size) between socially parasitic ants and their hosts has been reported; one explanation for this phenomenon is that a socially parasitic ant has to adapt to the host's colony environment (e.g., tunnel size) (Fischer et al. 2020). This phenomenon is probably also true for P. lamellidens and its hosts. The workers of ants in the subgenus Camponotus (C. japonicus and C. obscuripes belong to this subgenus) are 7-12 mm long, which is similar to or longer than P. lamellidens ( $7-9 \mathrm{~mm}$ for workers, $10 \mathrm{~mm}$ for the queen) (Japanese Ant Database Group 2003; Kohout 2014). Conversely, workers of the subgenera Myrmamblys and Myrmentoma (belonging to the genus Camponotus), which are not hosts of $P$. lamellidens, are less than $5 \mathrm{~mm}$ in total body length (Japanese Ant Database Group 2003).

This study revealed that $P$. lamellidens utilizes multiple ant species as a host (C. japonicus and $C$. obscuripes). In addition to $P$. lamellidens, socially parasitic ants that parasitize numerous hosts (e.g., Lasius umbratus) are known regardless of parasitism style. The common feature of these species is that the socially parasitic ants and their hosts tend to be closely related species, and the hosts belong to a specific taxonomic group at the subfamily level (Emery 1909; Hölldobler and Wilson 1990; Japanese Ant Database Group 2003; Huang and Dornhaus 2008; de la Mora et al. 2020).
The reason why the hosts are closely related to the parasitic ants and are restricted to few taxa is thought to be because it is easy for the parasitic ants to disguise their $\mathrm{CHC}$ profile (Blatrix and Sermage 2005; Huang and Dornhaus 2008; de la Mora et al. 2020); the same is probably true for P. lamellidens. Moreover, as mentioned, another factor in establishing social parasitism is that the host is closely related to the parasite species and can take care of the parasite's brood.

Our findings provide evidence, for the first time, of temporary social parasitism involving $P$. lamellidens and $C$. obscuripes. The methodology presented in this investigation will contribute to, and accelerate, the study of social insects.

Acknowledgements The authors thank Yuki Takai for technical supports. We would like to thank Haruhiko Sakai and Keizo Takasuka for helpful comments.

Author contributions HI, YK, and NK designed the project. HI performed all behavioral tests and rearing experiments. YK and NK performed molecular species identification. HI and YK collected ant specimens. The first draft of the manuscript was written by HI, and all the authors commented on previous versions of the manuscript. NK, MT, and KA managed the experimental environment. All the authors read and approved the final manuscript.

Funding Grants-in-Aid for JSPS Fellows, Taikichiro Mori Memorial Research Grants, Yamagata Prefecture, and Tsuruoka City.

Data availability The sequence data of cytochrome oxidase subunits I and II (COI/II) of P. lamellidens and C. obscuripes will be made available in Figshare (https://doi.org/10.6084/m9.figshare.13711843).

Code availability Not applicable.

\section{Declarations}

Conflict of interest The authors declare that they have no conflicts of interest.

Ethical approval Not applicable.

Consent to participate Not applicable.

Consent for publication Not applicable.

Open Access This article is licensed under a Creative Commons Attribution 4.0 International License, which permits use, sharing, adaptation, distribution and reproduction in any medium or format, as long as you give appropriate credit to the original author(s) and the source, provide a link to the Creative Commons licence, and indicate if changes were made. The images or other third party material in this article are included in the article's Creative Commons licence, unless indicated otherwise in a credit line to the material. If material is not included in the article's Creative Commons licence and your intended use is not permitted by statutory regulation or exceeds the permitted use, you will need to obtain permission directly from the copyright holder. To view a copy of this licence, visit http://creativecommons.org/licenses/by/4.0/. 


\section{References}

Akino T (2008) Chemical strategies to deal with ants: a review of mimicry, camouflage, propaganda, and phytomimesis by ants (Hymenoptera: Formicidae) and other arthropods. Myrmecol News 11(8):173-181

Blatrix R, Sermage C (2005) Role of early experience in ant enslavement: a comparative analysis of a host and a non-host species. Front Zool 2(1):1-7

Brady SG, Schultz TR, Fisher BL, Ward PS (2006) Evaluating alternative hypotheses for the early evolution and diversification of ants. Proc Natl Acad Sci USA 103(48):18172-18177

Buschinger A (2009) Social parasitism among ants: a review (Hymenoptera: Formicidae). Myrmecol News 12(3):219-235

de la Mora A, Sankovitz M, Purcell J (2020) Ants (Hymenoptera: Formicidae) as host and intruder: recent advances and future directions in the study of exploitative strategies. Myrmecol News 30:53-71

Degnan PH, Lazarus AB, Brock CD, Wernegreen JJ (2004) Hostsymbiont stability and fast evolutionary rates in an ant-bacterium association: cospeciation of Camponotus species and their endosymbionts, Candidatus Blochmannia. Syst Biol 53(1):95-110

Dettner K, Liepert C (1994) Chemical mimicry and camouflage. Annu Rev Entomol 39(1):129-154. https://doi.org/10.1146/annurev. ento.39.1.129

Emery C (1909) Über den ursprung der dulotischen, parasitischen und myrmekophilen ameisen. Biol Centralbl 29:352-362

Fischer G, Friedman NR, Huang JP, Narula N, Knowles LL, Fisher BL, Mikheyev AS, Economo EP (2020) Socially parasitic ants evolve a mosaic of host-matching and parasitic morphological traits. Curr Biol 30(18):3639-3646

Furukawa K, Ohbe T, Ito F (2012) Collection of a Polyrhachis lamellidens queen from a nest of Camponotus obscuripes (Hymenoptera: Formicidae). Bull Biol Soc Kagawa 39:61-62

Hölldobler B, Wilson EO (1990) The ants. The Belknap Press of Harvard University Press, Cambridge

Huang MH, Dornhaus A (2008) A meta-analysis of ant social parasitism: host characteristics of different parasitism types and a test of Emery's rule. Ecol Entomol 33(5):589-596

Iwai H, Horikawa DD, Arakawa K, Tomita M, Komatsu T, Maruyama M (2016) Rearing and observation of immature stages of the hoverfly Microdon katsurai (Diptera, Syrphidae). Biodivers Data J 4:e10185

Japanese Ant Database Group (2003) Ants of Japan. Gakken Plus, Tokyo
Johnson CA, Vander Meer RK, Lavine B (2001) Changes in the cuticular hydrocarbon profile of the slave-maker ant queen, Polyergus breviceps Emery, after killing a Formica host queen (Hymenoptera: Formicidae). J Chem Ecol 27(9):1787-1804

Kohout RJ (2014) A review of the subgenus Polyrhachis (Polyrhachis) Fr. Smith (Hymenoptera: Formicidae: Formicinae) with keys and description of a new species. Asian Myrmecol 6:1-31

Kohriba O (1963) A parasitic life of Polyrhachis lamellidens F. smith (Hymenoptera, Formicidae), first report. Kontyû 31:200-209

Kohriba O (1966) Record of mixed colony of Polyrhachis lamellidens F. Smith and Camponotus japonicus Mayr in the field. Kontyû 34:316

Kubota M (1974) Temporary social parasitism in Polyrhachis lamellidens $\mathrm{F}$. Smith. ARI 6:6

Kuraku S, Zmasek CM, Nishimura O, Katoh K (2013) aLeaves facilitates on-demand exploration of metazoan gene family trees on MAFFT sequence alignment server with enhanced interactivity. Nucleic Acids Res 41(W1):W22-W28

Lenoir A, d'Ettorre P, Errard C, Hefetz A (2001) Chemical ecology and social parasitism in ants. Annu Rev Entomol 46(1):573-599. https://doi.org/10.1146/annurev.ento.46.1.573

Maschwitz U, Dorow WHO, Buschinger A, Kalytta G (2000) Social parasitism involving ants of different subfamilies: Polyrhachis lama (Formicinae) an obligatory inquiline of Diacamma sp. (Ponerinae) in Java. Insectes Soc 47(1):27-35

Maschwitz U, Go C, Dorow WHO, Buschinger A, Kohout RJ (2003) Polyrhachis loweryi (Formicinae): a guest ant parasitizing Rhytidoponera sp. (Ponerinae) in Queensland, Australia. Insectes Soc 50(1):69-76

Sakai H (1990) Mixed colony of Polyrhachis lamellidens and Camponotus kiusiuensis. Insectarium 27:31

Sakai H (1996) Living life of Polyrhachis lamellidens - through rearing and field observation. Insectarium 33(8):232-235

Sakai H (2000) Observation and rearing of Polyrhachis lamellidens. Insectarium 37(3):78-83

Simon C, Frati F, Beckenbach A, Crespi B, Liu H, Flook P (1994) Evolution, weighting and phylogenetic utility of mitochondrial gene sequences and a compilation of conserved polymerase chain reaction primers. Ann Entomol Soc Am 87:651-701

Witte V, Lehmann L, Lustig A, Maschwitz U (2009) Polyrhachis lama, a parasitic ant with an exceptional mode of social integration. Insectes Soc 56(3):301-307

Yano M (1911) The Polyrhachis ants of Japan. Dobutsu-Gaku Zashi $23: 249-256$ 